\title{
Method for Continuously Rearing Coccinella Lady Beetles (Coleoptera: Coccinellidae)
}

\author{
Louis S. Hesler ${ }^{*}, 1$, Ginger McNickle ${ }^{2}$, Michael A. Catangui ${ }^{3}$, John E. Losey ${ }^{4}$, Eric A. Beckendorf ${ }^{1}$, \\ Leonard Stellwag ${ }^{4}$, Danielle M. Brandt ${ }^{2}$, and Pamela B. Bartlett ${ }^{2}$ \\ ${ }^{1}$ North Central Agricultural Research Laboratory, USDA-ARS, Brookings, SD 57006, USA \\ ${ }^{2}$ Plant Science Department, South Dakota State University, Brookings, SD 57007, USA \\ ${ }^{3} 47153$ S. Clubhouse Road, Sioux Falls, SD 57108, USA \\ ${ }^{4}$ Department of Entomology, Cornell University, Ithaca, NY 14853, USA
}

\begin{abstract}
Coccinella novemnotata L., the ninespotted lady beetle, and Coccinella transversoguttata richardsoni Brown, the transverse lady beetle, are predatory species whose abundance has declined significantly over the last few decades in North America. An ex situ system for continuously rearing these two beetles is described here to aid conservation efforts and facilitate studies aimed at determining factors in their decline and possible recovery. All rearing of lady beetles was conducted in the laboratory at or near room temperatures and 16:8 L:D photoperiod. The two coccinellid species were each reared separately, and different life stages were handled independently. Eggs were collected every 1 to $2 \mathrm{~d}$ and placed in holding containers, and individual clutches were transferred to cages with prey when their eggs began to hatch. Neonate larvae were fed live bird cherry-oat aphids [Rhopalosiphum padi (L.)] for 3 to $4 \mathrm{~d}$, and second instars were transferred to different cages and fed live pea aphids [Acyrthosiphon pisum (Harris)]. Third and fourth instars were also fed pea aphids, but reared individually in small cups to preclude cannibalism. Upon pupation, individuals were collectively transferred to fresh cups and placed in a different container for the duration of pupation. Newly emerged adults were collected within containers about $2 \mathrm{~d}$ after eclosion. Adults were housed in cages stocked with live pea aphids, supplemental food, and rumpled paper towels as oviposition substrate. Over $80 \%$ of egg clutches were deposited by beetles on rumpled paper towels versus other surfaces within cages, and incidence of cannibalism of egg clutches was greatly reduced on rumpled paper towels. Techniques for successful rearing of these two coccinellids and future research regarding adaptations to further optimize their rearing methods are discussed.
\end{abstract}

Keywords: Coccinella novemnotata, Coccinella transversoguttata, Coccinella septempunctata, bird cherry-oat aphid, pea aphid, insect conservation.

\section{INTRODUCTION}

Coccinella novemnotata L., the ninespotted lady beetle, and Coccinella transversoguttata richardsoni Brown, the transverse lady beetle, are predaceous species that were previously common throughout North America, but their abundance has declined in crop fields over the last three decades [1-4]. Research is needed to understand reasons for the decline, and some research may occur in areas with extant beetle populations [5]. However, understanding reasons for their decline may be facilitated by additional field and laboratory studies that rely on supplemental $C$. novemnotata and $C$. transversoguttata richardsoni reared ex situ. Moreover, as the status of wild beetle populations is unclear, ex situ breeding may be an advisable conservation measure [6]. These reasons underscore the need to develop methods for rearing $C$. novemnotata and C. transversoguttata richardsoni.

Both C. novemnotata and C. transversoguttata richerdsoni are principally aphidophagous on a wide variety of

*Address correspondence to this author at the USDA-ARS-NCARL 2923 Medary Ave. Brookings, SD 57006 USA; Tel: +1 605693 5228;

E-mail: louis.hesler@ars.usda.gov aphids, including many crop pests $[1,7,8]$. They have been reared for short-term studies on relatively few kinds of aphids, but the pea aphid, Acyrthosiphon pisum (Harris), is suitable prey for rearing both coccinellids [8,9]. Although pea aphid is native to Europe and was introduced into North America in the $1800 \mathrm{~s}$ [10], C. novemnotata and $C$. transversoguttata richardsoni readily feed on this aphid and were formerly common predators of it in North America [913].

Successful ex situ rearing of Coccinella species depends on various biological and behavioral aspects of the beetles $[14,15]$. For instance, reproductive behavior of coccinellids is sensitive to daylength $[16,17]$. Relatively short daylengths induce reproductive diapause in coccinellids, whereas reproduction may be sustained using photoperiods of at least 14 hrs with C. transversoguttata richardsoni [18] and 16 hrs with C. novemnotata [19].

Cannibalism and interspecific predation are behavioral features of predaceous coccinellids [8]. Sessile stages (eggs, molting larvae, pupae) are often prey for active beetles, and smaller larvae are generally vulnerable to predation by larger ones $[8,20]$. Cannibalism and interspecific predation are two 
of the most important mortality factors for coccinellids, and cannibalism is a major challenge to their simple mass production $[8,21]$. Isolation of individual coccinellids soon after hatching greatly decreases cannibalism, but this measure is typically impractical for mass rearing $[8,22]$.

Practical alternatives have been devised to minimize cannibalism and improve efficiency in mass rearing operations. For instance, provision of egg-laying refuges that differentially attract reproductive females over other individuals leads to increased oviposition and decreased egg predation $[17,22]$. Cannibalism of various stages may be minimized by adding materials that increase surface area and thereby the effective travel distances between individuals [17], and by ensuring adequate non-coccinellid prey within cages [21,23].

The use of a particular prey or mix of prey species may be fine-tuned by comparing relative suitability of different aphid diets for various coccinellid species [8,24]. The use of single vs. mixed aphid species may also affect rearing outcomes. For instance, even though diets of mixed aphid species may be more nutritionally diverse, they are not necessarily better for rearing a congeneric species, Coccinella septempunctata L. $[25,26]$. However, there are additional considerations with regard to rearing coccinellids on singleaphid vs. dual-aphid species diets, such as feeding differentially-sized aphids to specific larval instars [27]. The pea aphid is relatively large, and our initial observations suggested that individual first- and second-instar coccinellid larvae have difficulty subduing late-instar nymphs and adult pea aphids. Provision of smaller aphid prey might improve feeding efficiency and success of early instars.

Given various factors discussed above, we surmised that a rearing system that used a long photoperiod; provided refugia; and supplied two aphid species to different coccinellid instars could produce a system for continuously rearing $C$. novemnotata and $C$. transversoguttata richardsoni. In this paper, we describe a successful tritrophic system for rearing Coccinella novemnotata and $C$. transversoguttata richardsoni, and discuss limitations that should prompt further research to improve rearing conditions for these coccinellids.

\section{PROCEDURES}

\section{Overview}

Lady beetles were reared at the USDA-ARS North Central Agricultural Research Laboratory (NCARL), Brookings, South Dakota, USA, in environmental chambers (Conviron, Winnipeg, Manitoba, Canada) set with a 16:8 (L:D) photoregime and $22^{\circ} \mathrm{C}: 18^{\circ} \mathrm{C}$ (L:D) temperature range. The two coccinellid species were reared individually, and different life stages were handled separately. In brief, eggs were collected every 1 to $2 \mathrm{~d}$ and placed in holding containers, and individual clutches were transferred when their eggs began to hatch. Neonate larvae were transferred to 3.5-liter cages containing bird cherry-oat aphids [BCOA, Rhopalosiphum padi (L.)] as prey, and 3 to $4 \mathrm{~d}$ later second instars were transferred to analogous cages containing pea aphids as prey. Third and fourth instars were reared individually in small cups with pea aphids. Prepupae and pupae were transferred to fresh cups and collectively placed in cages. Newly emerged adults were collected within the cages about $2 \mathrm{~d}$ after eclosion. Adults were housed in cages stocked with pea aphids, supplemental food, and oviposition substrate. Details follow regarding the rearing of aphid prey and procedures used to rear Coccinella beetles during specific life stages.

\section{Aphids}

BCOA were obtained from a virus-free, multiclonal stock colony maintained on barley plants in environmental chambers at $\left(19^{\circ} \mathrm{C}, 50 \% \mathrm{RH}, 13: 11 \mathrm{~L} / \mathrm{D}\right)$ at NCARL. The colony was established by collecting aphids from a wheat field in Brookings County, South Dakota, in summer 2009 and reestablished in 2010 with aphids from a wheat field near Stillwater, Oklahoma, USA. The colony was perpetuated by regularly infesting two-week-old barley plants with winged BCOA. Winged aphids were used to infest plants, and these were taken from colony plants infested 24 to $27 \mathrm{~d}$ earlier.

Barley was grown in 1.7-liter pots containing a mix of 2 parts sifted soil, 1 part vermiculite (Thero-O-Rock West, Inc., Chandler, AZ), and 1 part peat moss (Waupaca Northwoods LLC, Waupaca, WI). Osmocote slow-release fertilizer (14-14-14, N-P-K; The Scotts Company LLC, Marysville, $\mathrm{OH}$ ) was placed $2.5 \mathrm{~cm}$ below seeds at planting. Fifty barley seeds were placed in the center of a pot and covered with $2.5 \mathrm{~cm}$ of soil mix. Seedlings were allowed to develop $1 \mathrm{wk}$ in a greenhouse $\left(23^{\circ} \mathrm{C}, 50 \% \mathrm{RH}, 13: 11 \mathrm{~L} / \mathrm{D}\right)$, then transferred to an environmental growth chamber $\left(19^{\circ} \mathrm{C}\right.$, $50 \% \mathrm{RH}, 13: 11 \mathrm{~L} / \mathrm{D}$ ) and infested with about 50 BCOA of various stages on clipped leaves of colony plants. Aphids populated barley plants for 2 wks before introduction into rearing cages for first-instar lady beetles.

Pea aphids were obtained from alfalfa fields near Brookings, and reared on Austrian winter pea grown in 1.7-liter pots containing soil mix as above. At planting, 20 pea seeds were grouped in the center of each pot, sprinkled with inoculant "S" culture [Bradyrhizobium japonicum (Kirchner), Nitragin, Milwaukee, WI)], and covered with $2.5 \mathrm{~cm}$ of soil mix. Pea seedlings developed for $10 \mathrm{~d}$ in a greenhouse $\left(23^{\circ}\right.$ C, $50 \% \mathrm{RH}, 16: 8 \mathrm{~L} / \mathrm{D}$ ), were transferred to an environmental chamber $\left(23^{\circ} \mathrm{C}, 50 \% \mathrm{RH}, 16: 8 \mathrm{~L} / \mathrm{D}\right)$, and infested by gently shaking a pot of aphid-infested plants to dislodge pea aphids onto new plants. Pea aphid populations built-up on newly infested plants for $10 \mathrm{~d}$ in an environmental chamber and were then transferred to beetle-rearing cages.

\section{Adults}

Colonies were established by field collection of adult beetles. Adult $C$. novemnotata were field-collected from southwestern South Dakota, USA, in summer 2008 and from southern Oregon, USA, in summer 2009. Adult $C$. transversoguttata richardsoni were obtained from a temporary colony of field-collected beetles from eastern Washington, USA, in 2009 and from field-collected beetles from northern Utah, USA, in 2010.

Colony cages for adult beetles consisted of 25.5-liter plastic totes (Fig. 1a; Sterilite, Townsend, MA) with six, 5.1$\mathrm{cm}$ holes for aeration on the sides and two on the lid, all covered with aphid-proof mesh screen (BioQuip, Gardena, CA). Spongy weather-strip tape $(0.95-\mathrm{cm}$ wide x $0.79-\mathrm{cm}$ high; 


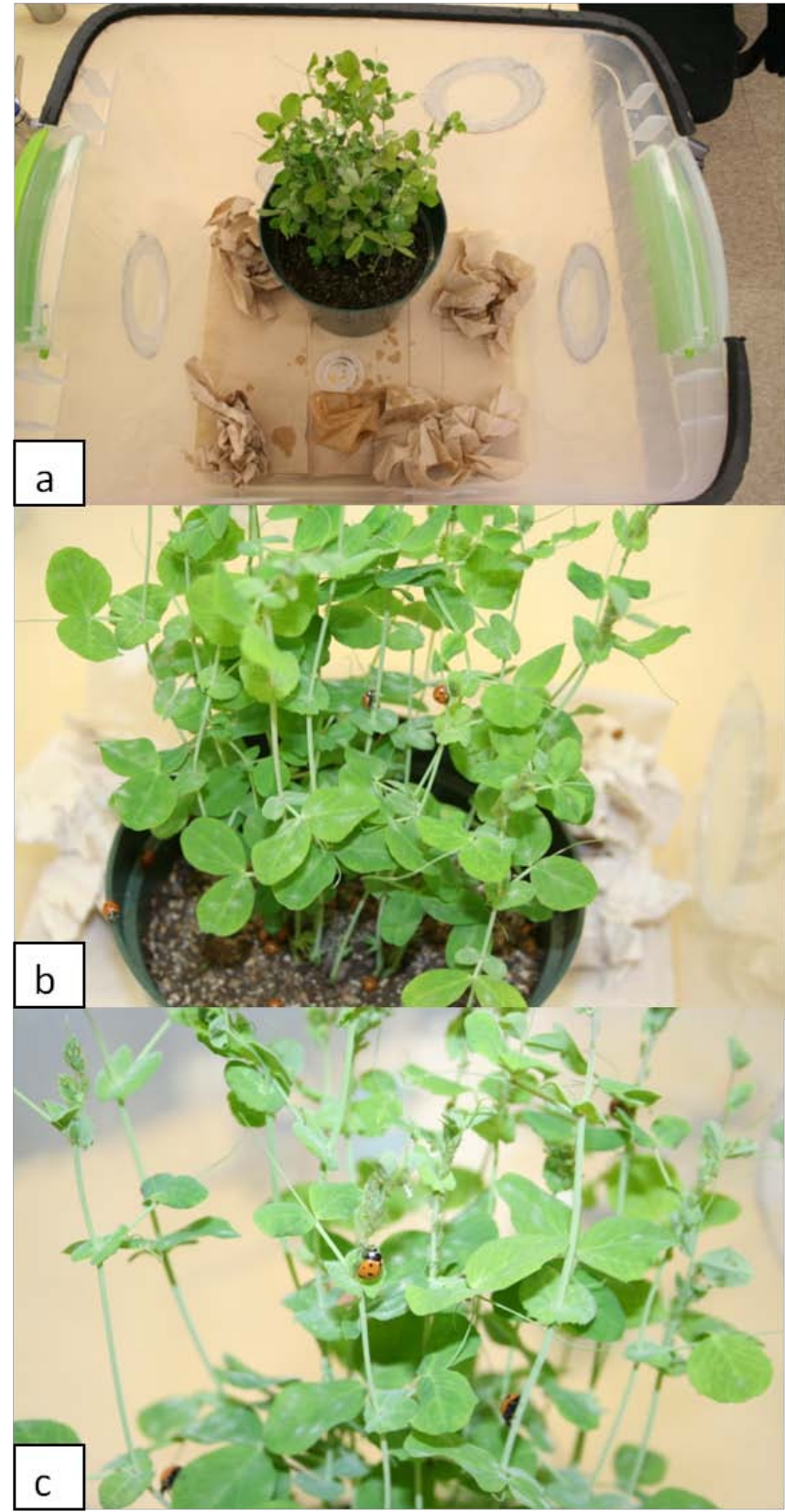

Fig. (1). (a) Adult cage base with potted, winter pea plants, paper hand towels lining floor, crumpled paper towels as oviposition substrate, moistened paper towel as water source, small lid with supplemental food (pollen, arthropod eggs). (b) Adult beetles on soil and winter pea plants. (c) Close up of Coccinella novemnotata feeding on pea aphids.

Henkel Consumer Adhesives, Avon, $\mathrm{OH}$ ) was glued to the lip of the tote to provide a more secure seal with the lid.

Sixty to 75 adult beetles were placed in a rearing cage (Fig. 1b,c). The floor of each container was lined with two, paper hand towels. A pot containing 20-35 Austrian winter pea plants (Lathyrus hirsutus) plants moderately infested with $A$. pisum was set on the cage floor. Supplemental food was provided on a small plastic dish (6- $\mathrm{cm}$ diam), including five small granules of bee pollen (Fresh Bee Pollen Whole Granules, Y.S. Organic Bee Farms, Sheridan, IL, or Bee-Pro
Honey Bee Pollen Substitute, Mann Lake LTD, Hackensack, $\mathrm{MN}$ ), powdered meal (Good Bug Power Meal TM, Arbisco Environmentals, Tucson, AZ), and ad libitum eggs of Indianmeal moth (Ephestia kuehniella Zeller, Lepidoptera: Pyralidae; Beneficial Insectary, Redding, CA) and brine shrimp (Artemia salina, Anostraca: Artemiidae; Ocean Start International, Snowville, UT). Water was provided by folding two paper towels and placing them in a 50-ml beaker with water. Adults were gently aspirated and transferred to new cages with new aphid-infested plants every $2 \mathrm{~d}$ because of food consumption and soiling of materials.

Although adult females laid eggs on pea plants and other surfaces within the cages (Fig. 2a), specific oviposition substrate was added to increase efficiency of egg collection. The substrate consisted of three to four rumpled, white or brown, paper towels (Fig. 2b). Lady-beetle eggs laid on this substrate (Fig. 2c) were removed roughly daily to track ages of individual egg clutches and to minimize egg cannibalism. Portions of towels with individual clutches were cut out and placed into small cylindrical, vented, plastic containers (6$\mathrm{cm}$ ht $\mathrm{x}$ 15-cm diam; Fig. 2d) that were held in a growth chamber until hatching (CMP 3245, Conviron, Winnipeg, Canada) at $23^{\circ} \mathrm{C}, 49 \% \mathrm{RH}, 16: 8 \mathrm{~h}$ (L:D) [9].

\section{First and Second Instars}

Upon hatching, neonate larvae and the remaining egg clutch were placed into a new container in which the floor was lined with two to three paper towels to absorb condensation and littered with crumpled paper towels as a molting substrate (Fig. 3). Leaves of barley (cv. 'Robust') heavily infested with BCOA were clipped and laid within the container. Supplemental food of bee pollen, powdered meal, moth eggs, and brine shrimp eggs were provided in the same manner as for adults. Two days later, most larvae had become second instars and were transferred to fresh cages with analogous set up, except that stems of winter pea plants infested with pea aphids were used as the primary food source for 75 to 100 larvae per cage.

\section{Third and Fourth Instars}

Third-instar larvae were individually placed in 29.6-ml containers (Fig. 4a; Bio-Serv, Frenchtown, NJ). The lid of each container had five or six small aeration holes punctured by using a needle-point tool. Approximately 25 pea aphids on winter pea leaves and stems were placed as a food source in each container. Other aphids (e.g., BCOA on barley, soybean aphid (Aphis glycines Matsumura) on soybean) were occasionally substituted for pea aphids. Containers were placed in a tray with wells to hold individual cups and checked daily to ensure adequate prey (Fig. $\mathbf{4 b}$ ). Larvae were transferred to fresh containers every two days.

\section{Prepupae, Pupae, and Teneral Adults}

Large, quiescent fourth instars (i.e. prepupae [15]) had typically settled on winter pea leaves or their holding containers. Individual prepupae / pupae, and cups and lids with attached individuals were carefully transferred to a new holding container for the duration of pupation (Fig. 5). 


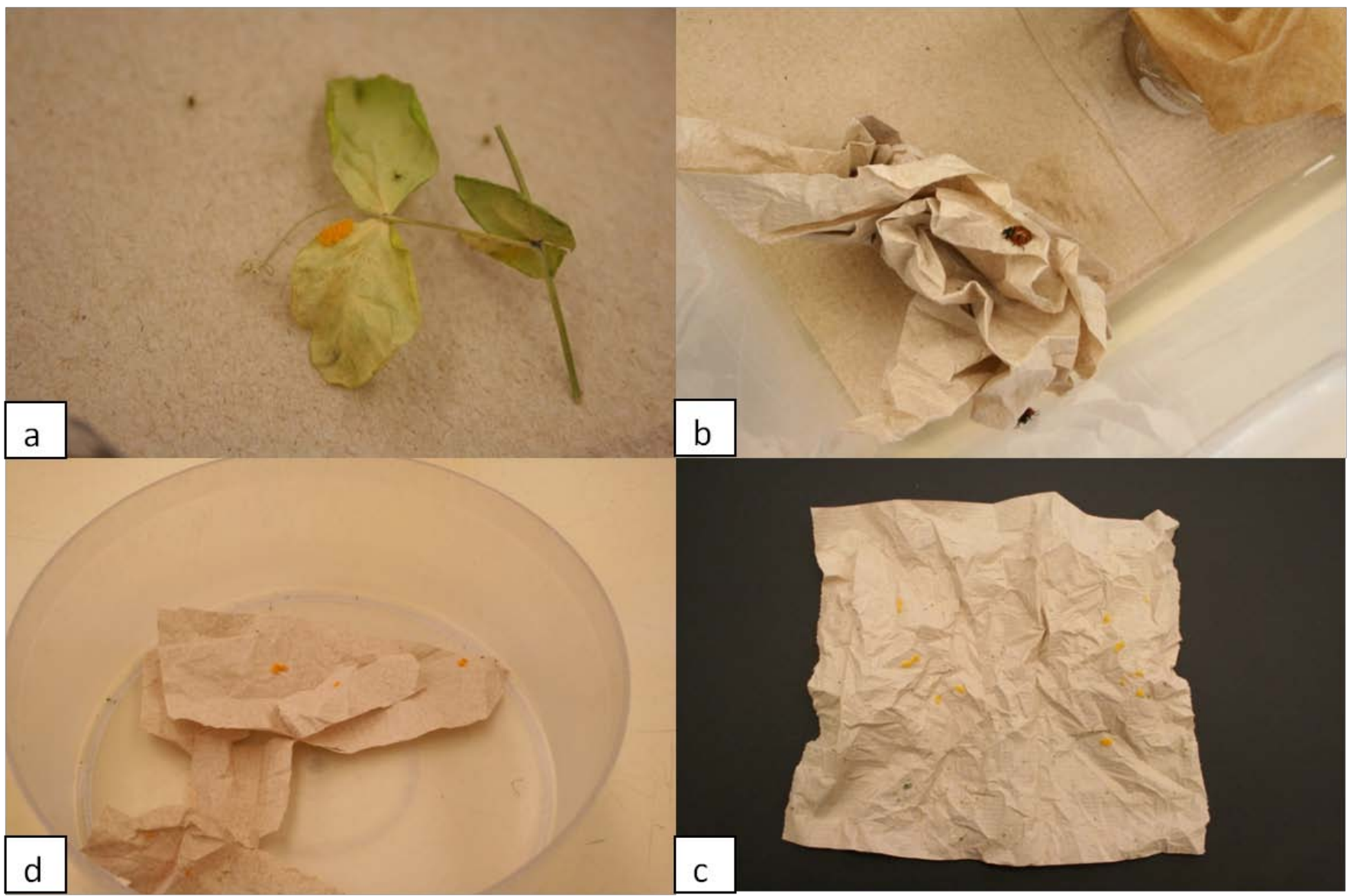

Fig. (2). (a) Eggs of Coccinella transversoguttata richardsoni on leaf of winter pea. (b) Adult Coccinella transversoguttata richardsoni on crumpled paper towels used as oviposition substrate. (c) Eggs deposited on previously crumpled paper hand towel. (d) Cuttings of paper towel with coccinellid eggs.

Teneral adults remained for 24 to $48 \mathrm{~h}$ in pupation cages until elytral spots were clearly discernible and the cuticle had sclerotized. The new adults were then collected and placed with other, older adults in a tote cage.

\section{RESULTS AND DISCUSSION}

We have used the method described above to successfully rear over 15 continuous generations each of $C$.

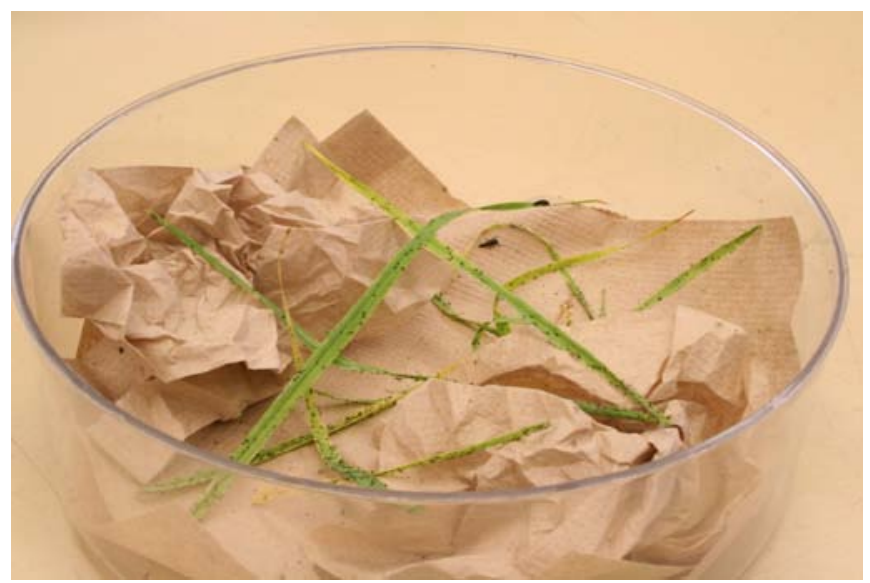

Fig. (3). Second-instar coccinellids with clippings of aphid-infested barley housed in cylindrical container (without lid). novemnotata and C. transversoguttata richardsoni in our labs, and we have also adapted them to successfully rear multiple generations of $C$. septempunctata. Several practical points for rearing Coccinella were discovered empirically in this study.

First, housing 60 to 75 adult beetles per cage was optimal for handling adult beetles. Housing that range of beetles of mixed sex allowed for assortive mating, and logistically, handling that many beetles was manageable especially during transfer, when the beetles could fly or crawl away. A number of beetles in that range could be quickly aspirated by a single individual for transfer to a new cage, whereas escapees became increasingly problematic at higher adult densities.

Earlier observations indicated that egg production was limited, especially in cages with $>>75$ adult beetles. That is, we often found no egg clutches over a $24 \mathrm{hr}$ period at $>75$ adults per tote, whereas this rarely happened at densities of roughly 60 adults per tote. These densities of adult Coccinella beetles possibly decreased mating success or caused gravid females to withhold eggs. High adult densities resulted in decreased oviposition in a laboratory rearing system for the lady beetle, Coleomegilla maculata DeGeer [22], and gravid lady beetles under laboratory conditions generally oviposit less when other lady beetles are present [28]. 


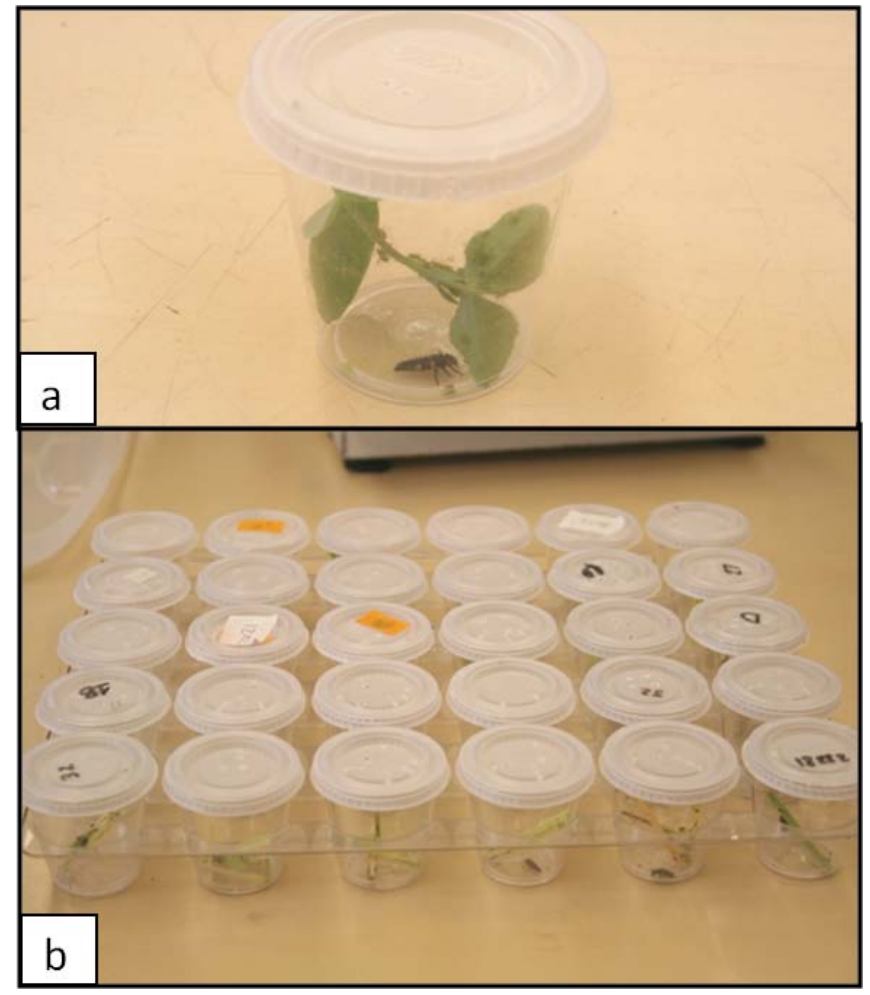

Fig. (4). (a) Individual coccinellid larva in 29.6-ml rearing cup with aphid-infested plant cuttings. (b) Tray of larval rearing cups.

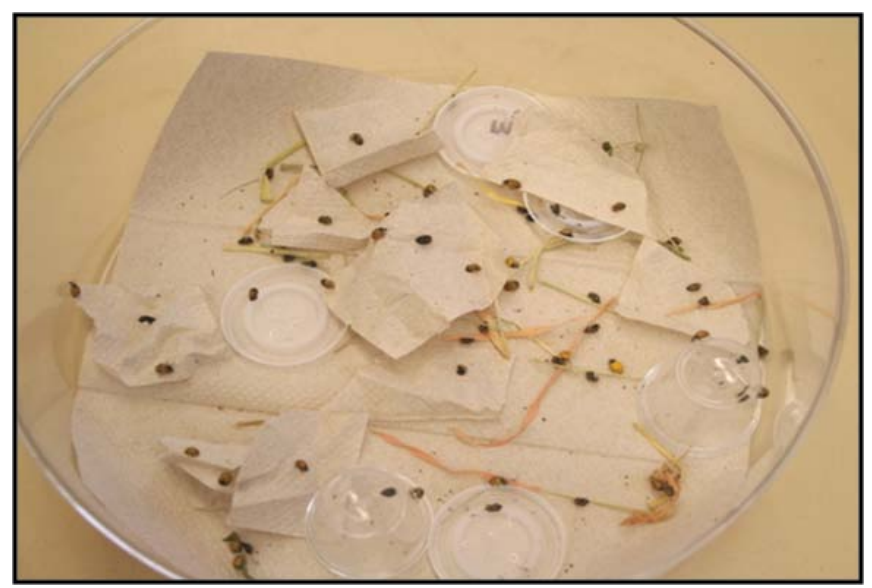

Fig. (5). Pupae and teneral adults on paper towels and individual lids in small holding container (without top).

Although moderation of adult densities may have been responsible for improved egg production in our system, inspection of egg clutches in adult cages nevertheless showed sporadic, but often high incidence of pre-hatch cannibalism. The eggs were deposited generally unconcealed throughout the cages on walls and ceiling, on flat paper towels, and on pea plants and pots, and thus they were readily discovered and consumed by adult beetles. This frequently resulted in no or greatly reduced viability of egg clutches. However, when rumpled paper towels were placed as oviposition substrates in adult cages, $\geq 80 \%$ of egg clutches were deposited by beetles on them, mainly within shaded crenulations. As such, incidence of pre-hatch egg cannibalism became infre- quent on rumpled paper towels, and this greatly contributed to rearing success.

Our observations of oviposition and cannibalism also suggest spatial partitioning by various adult Coccinella, namely that rumpled paper towels were frequented by ovipositing females but infrequently visited by foraging adults. Similarly, Shands et al. [17] found that egg-laying refuges that differentially attracted reproductive females led to increased oviposition and decreased egg predation in $C$. septempunctata. Allen and Riddick [22] found that waxed strips hung for oviposition by C. maculata were also used by resting and mating adults, and that the strips facilitated harvesting of eggs without need to anaesthetize adult beetles.

Use of rumpled paper towels in cages housing first and second larval instars also decreased cannibalism of molting larvae. We often observed individual, actively foraging larvae biting and sometimes feeding upon sessile larvae, even though larvae were provided with an ad libitum supply of aphids and non-prey food. However, addition of rumpled paper towels to cages resulted in decreased observations of cannibalism and fewer larval cadavers noticed when larvae were transferred to new totes. The rumpled towels were unlikely to be searched by actively foraging larvae and thus provided a refuge for molting larvae. Similarly, Shands et al. [17] found reduced cannibalism in C. septempunctata by addition of materials that augmented surface area within rearing cages and thereby increased the effective distances and encounters between individuals.

The substitution of bird cherry-oat aphids for pea aphids as prey for first-instar larvae increased graduation of larvae to the second stadium. This might have resulted from improved nutrition, enhanced capture efficiency by first instars, or both. Nutritionally, a mixture of aphid prey raised on different plants may diversify nutrient composition and improve performance of coccinellid larvae. However, Nielsen et al. [26] found no benefit from mixing aphid species (including BCOA) in the diet of C. septempunctata, and quality of mixed diets depended on suitability of constituent prey species rather than host plants on which aphids were reared.

Alternatively, suitability of an aphid species as prey is most influenced by capture efficiency, and capture efficiency is related to prey size $[27,29]$. BCOA are about half the size of pea aphids [30], and thus may have been easier to subdue than pea aphids particularly for first instars. In addition, we have also successfully reared $C$. novemnotata on an alternative mixed diet of pea aphid and green peach aphid, Myzus persicae (Sulzer), which is comparable in size to BCOA [31]. Logistically, it may be simpler to maintain only one kind of aphid in support of rearing Coccinella, but, in addition to potentially providing differentially sized prey, supporting two (or more) aphid species helps ensure that at least one acceptable prey species is available in case of shortages in the other.

The aphid-plant system described here produced about 300 beetles per species on average in roughly 3 weeks. Thus, this system is adequate for maintaining viable captive populations of Coccinella spp. to supply laboratory experiments and possibly field experiments. The system is also potentially amenable for re-introductions of $C$. novemnotata and $C$. 
transversoguttata richardsoni in to the field [6]. It could be used either to transfer a few hundred beetles into field cages to allow build up of populations for eventual release from the cages, or to make repeated releases of a few hundred beetles at a time into a particular area. Alternatively, the rearing system could be scaled-up for mass release (e.g., several thousands) of beetles directly into the field, but this would require additional labor, space, and materials.

The rearing procedures we describe here incur various costs for labor, utilities (water; electricity for light, temperature regulation, etc.), supplies and materials. Caretaking of beetles, aphids, and plants has required a minimum of 2 employees for 18 hrs per week at a wage of roughly \$10 (USD), or $\$ 1080$ for the 3-week minimum period to rear one cohort of beetles. Monitoring electrical usage was not practical for individual chambers and rooms devoted to rearing plants, aphids, and beetles. Nonetheless, technical personnel estimate a minimum of $\$ 10$ per day per growth chamber in electricity, or $\$ 210$ per cohort. Additional costs are associated with lighting work rooms and greenhouses, watering plants, and cleaning cages and reusable materials, for further costs of conservatively $\$ 100$ per cohort. Expendable supplies (soil mix, seed, soap, paper hand towels, light bulbs, etc.) and durable materials (totes, pots, cups, etc.) are purchased in bulk, and thus are pro-rated per cohort at an estimated cost of at least $\$ 100$ each. Altogether, we conservatively estimate that rearing one generation of beetles in a 3-week period costs nearly $\$ 1600$, or more than $\$ 5$ on average per adult beetle produced. Costs for land, administrative overhead, and other items not considered add to the cost of this rearing procedure.

Nonetheless, methods described in this paper provide a foundation for rearing at least three Coccinella species. Further work is needed to quantify advantages inherent in this rearing system, such as the availability of refugia for oviposition and reduced incidence of pre-hatch egg cannibalism. Additional experiments may also be conducted to further optimize the system such as the favorability of particular aphid prey or factitious diets. For instance, our rearing system for Coccinella uses one or more species of live aphids, and thus requires production of host plants and aphid prey in order to support coccinellids. Drawbacks to this system include its vulnerability to discontinuity occurring at one of these levels, and requirement for a substantial amount of labor, frequent attention, and a large amount of space [32]. However, factitious diets may be suitable alternatives to rearing coccinellids with live aphids [14,33], and if developed for Coccinella beetles, might be more cost effective by eliminating space needed to grow plants and aphids, and by greatly reducing utilities and labor required. Future efforts are needed to develop pre-fabricated, factitious diets for Coccinella and other potential adaptations to this rearing system, and to compare their cost and production efficiency with the tritrophic system described here.

\section{ACKNOWLEDGEMENTS}

Eric Riddick, Andrei Alyokhin and Sharon Papiernik reviewed drafts of this paper. Sara Haberling, Sara Ackman, Ryan Ackman, Corrinna Schwartz, Philip Rozeboom, Mallory Burtz, Megan Wentzel, and Mallory Wentzel assisted in colony maintenance. Tobin Northfield, Bill Snyder, and Ted Evans graciously shipped coccinellids to us. This work was supported in part by a grant from the National Science Foundation, award number DRL-0741738, to J.E.L., M.A.C. and L.S.H., and by base funding under USDA-ARS CRIS Project No. 5447-21220-005-00D to L.S.H.

\section{CONFLICT OF INTEREST}

The authors confirm that this article content has no conflicts of interest.

\section{REFERENCES}

[1] Gordon RD. The coccinellidae (Coleoptera) of America north of Mexico. J New York Entomol Soc 1985; 93: 1-912.

[2] Wheeler Jr AG, Hoebeke ER. Coccinella novemnotata in northeastern North America: historical occurrence and current status (Coleoptera: Coccinellidae). Proc Entomol Soc Wash 1995; 97: 701-16.

[3] Harmon JP, Stephens E, Losey J. The decline of native coccinellids (Coleoptera: Coccinellidae) in the United States and Canada. J Insect Conserv 2007; 11: 85-94.

[4] Fothergill K, Tindall KV. Lady beetle (Coleoptera: Coccinellidae: Coccinellinae) occurrences in southeastern Missouri agricultural systems: differences between 1966 and present. Coleopt Bull 2010; 64: 379-82.

[5] Hesler LS, Losey JE, Catangui MA, Helbig JB, Mesman A. Recent records of Adalia bipunctata (L.), Coccinella transversoguttata richardsoni Brown, and Coccinella novemnotata Herbst (Coleoptera: Coccinellidae) from South Dakota and Nebraska. Coleopt Bull 2009; 63: 475-84.

[6] New TR. Beetles in conservation. New York, NY, USA: WileyBlackwell 2010.

[7] Wheeler AG. Jr. Studies on the arthropod fauna of alfalfa: VII Predaceous insects. Can Entomol 1977; 109: 423-7.

[8] Hodek I. Food relationships. In: Hodek I, Horěk A, Eds. Ecology of Coccinellidae. Dordrecht, The Netherlands: Kluwer Academic Publishers 1996; pp. 143-238.

[9] McMullen RD. The effects of photoperiod, temperature, and food supply on rate of development and diapause in Coccinella novemnotata. Can Entomol 1967; 99: 578-86.

[10] Thomas C. A list of the species of the tribe Aphidini, family Aphidae, found in the United States, which has been heretofore named with descriptions of some new species. Illinois State Lab Nat Hist Bull 1878; 2: 3-16.

[11] Pack HJ. A biological study of certain ladybird beetles (Coccinellidae). Ph.D. dissertation. Ithaca, NY, USA: Cornell University 1925.

[12] Stehr WC. The Coccinellidae of Minnesota. Univ Minnesota Agric Experiment Station Tech Bull 1930; 75: 1-54.

[13] Knowlton GF, Smith CF, Harmston FC. Pea aphid investigations. Proc Utah Acad Sci 1938; 15: 71-80.

[14] Singh P. Insect diets--Historical developments, recent advances and future prospects. In: King EG, Leppla NC, Eds. Advances and Challenges in Insect Rearing. USA: US. Govt. Printing Office 1984; pp. 32-44.

[15] Honěk A. Life history and development. In: Hodek I, Hĕkn A, Eds. Ecology of Coccinellidae. Dordrecht, The Netherlands: Kluwer Academic Publishers 1996, pp. 61-93.

[16] Hodek I. Dormancy. In: Hodek I, ElonA, Eds. Ecology of Coccinellidae. Dordrecht, The Netherlands: Kluwer Academic Publishers 1996; pp. 239-318.

[17] Shands, WA, Holmes RL, Simpson GW. Improved laboratory production of eggs of Coccinella septempunctata. J Econ Entomol 1970; 63: 315-7.

[18] Storch RH. The effect of photoperiod on Coccinella transversoguttata (Coleoptera: Coccinellidae). Entomol Exp Appl 1973; 16: 77-82

[19] McMullen RD. A field study of diapause in Coccinella novemnotata (Coleoptera: Coccinellidae). Can Entomol 1967; 99: 42-9.

[20] Cottrell TE. Lady beetle egg predation on initial contact by adult and larval lady beetles. Environ Entomol 2008; 36: 390-401. 
[21] Schellhorn NA, Andow DA. Mortality of coccinellid (Coleoptera Coccinellidae) larvae and pupae when prey become scarce. Environ Entomol 1999; 28: 1092-100.

[22] Allen M, Riddick E. A system for collecting eggs of the pinkspotted lady beetle. Psyche 2012; [E-Pub ahead of Print].

[23] Sato S, Shinya K, Yasuda H, Kindlmann P, Dixon AFG. Effects of intra and interspecific interactions on the survival of two predatory ladybirds (Coleoptera: Coccinellidae) in relation to prey abundance. Appl Entomol Zool 2009; 44: 215-21.

[24] Michaud JP. On the assessment of prey suitability in aphidophagous Coccinellidae. Eur J Entomol 2005; 102: 385-90.

[25] Hauge SM, Nielsen FH, Toft S. The influence of three cereal aphid species and mixed diet on larval survival, development and adult weight of Coccinella septempunctata. Entomol Exp Appl 1998; 89: 319-22.

[26] Hauge SM, Nielsen FH, Toft S. The influence of mixed aphid diets on larval performance of Coccinella septempunctata (Col. Coccinellidae). J Appl Entomol 2002; 126: 194-7.
[27] Sloggett JJ. Weighty matters: body size, diet and specialization in aphidophagous ladybird beetles (Coleoptera Coccinellidae). Eur J Entomol 2008; 105: 381-9.

[28] Seagraves MP. Lady beetle oviposition behavior in response to the trophic environment. Biol Control 2009; 51: 313-22.

[29] Mills NJ. Essential and alternative foods for some British coccinellids (Coleoptera). Entomol Gaz 1981; 32: 197-202.

[30] Blackman RL, Eastop VF. Aphids on the world's herbaceous plants and shrubs. Vol. 2. New York: John Wiley \& Sons 2006.

[31] Losey J, Perlman J, Kopco J, et al. Decreased size in field populations of Coccinella novemnotata: Implications for range contraction and decreased densities. Biol Control 2012; 61: 98103.

[32] Bonte M, Samih MA, de Clercq P. Development and reproduction of Adalia bipunctata on factitious and artificial foods. Bio Control 2010; 55: 485-91.

[33] Sarwar M, Saqib SM. Rearing of predatory seven spotted ladybird beetle Coccinella septempunctata L. (Coleoptera: Coccinellidae) on natural and artificial diets under laboratory conditions. Pak J Zool 2010; 42: 47-51.

(c) Hesler et al.; Licensee Bentham Open.

This is an open access article licensed under the terms of the Creative Commons Attribution Non-Commercial License (http://creativecommons.org/licenses/ by-nc/3.0/) which permits unrestricted, non-commercial use, distribution and reproduction in any medium, provided the work is properly cited. 